\title{
LOS DUELOS Y QUEBRANTOS DE BARTOLOMÉ JOSÉ GALLARDO: EL LENGUAJE Y LA COMUNICACIÓN DE LA SÁTIRA MODERNA EN SU DICCIONARIO CRÍTICO-BURLESCO
}

\author{
THE BARTOLOMÉ JOSÉ GALLARDO'S DUELOS \\ $Y$ QUEBRANTOS: THE LANGUAGE AND THE \\ COMMUNICATION OF THE MODERN SATIRE \\ IN THE DICCIONARIO CRÍTICO-BURLESCO
}

\section{Alberto ROMERO FERRER}

Universidad de Cádiz

alberto.romero@uca.es

Resumen: El objetivo de este trabajo es subrayar las calidades grotescas del Diccionario crítico-burlesco (1811), de Bartolomé José Gallardo: filólogo, erudito, bibliógrafo, poeta, periodista y polemista de muy singular significación en la literatura española del primer tercio del siglo XIX, e injustamente denostado debido a su famoso Diccionario. Una obra especialmente importante, pues inaugura la sátira moderna en el pensamiento y la cultura española en permanente diálogo con la estética grotesca de los grabados y las Pinturas negras de Francisco de Goya, de acuerdo también con la mejor tradición burlesca de la literatura barroca e ilustrada. 
Abstracts: The purpose of this work is to study the grotesque aesthetics on Bartolomé José Gallardo's Diccionario crítico-burlesco (1811). Gallardo was a philologist, scholar, bibliographer, poet, journalist and debater of very singular significance in the Spanish literature of the first third of the nineteenth century, and was unjustly reviled due to his famous and polemical Diccionario. A crucially important work, in that it opens the modern satire in Spanish culture and thought, the Diccionario was in permanent dialogue with the grotesque aesthetics of Francisco de Goya's Caprichos and Pinturas negras, as well as with the best burlesque tradition of baroque culture and literature of the eighteenth century. A literary work that merits masterpiece status because it represents the vision of a major writer in contact, and often in conflict, with the common beliefs and behavior of his times.

Palabras claves: Gallardo. Diccionario crítico-burlesco. Sátira. Estética grotesca.

Key words: Gallardo. Diccionario crítico-burlesco. Satire. Grotesque aesthetics.

Ya que se ha puesto al error en diccionario, se debe poner también a la verdad.

Diccionario antifilosófico, por el abate Claudio Adriano Nonote (1793)

Lo grotesco imita plásticamente a la naturaleza en periodo de transformación y evolución; de aquí que sus manifestaciones sean monstruosas a la par que bellas.

Ramón Pérez de Ayala

\section{INTRODUCCIÓN: LA UTILIZACIÓN GROTESCA DE CERVANTES}

El Diccionario crítico-burlesco (1811) ${ }^{1}$, de Bartolomé José Gallardo es una obra de singular importancia en la cultura literaria y política española del primer tercio del siglo XIX, cuya excepcionalidad la convierte en uno de los estigmas que perseguirán a su autor a lo largo de su injustamente denostada trayectoria intelectual y literaria (Sainz Rodríguez, 1921), por motivaciones,

1 Este trabajo se encuadra en el Proyecto de Investigación Historia de la Literatura Española entre 1808 y 1833, referencia FFI2010-15098 del Plan Nacional de I+D+I del Gobierno de España. 
en principio, de tipo político, pero que muy pronto derivarán hacia posicionamientos filológicos y literarios (Pérez Vidal, 1999: 13-15). El caso, tal vez, más significativo son los juicios desfavorables que don Marcelino Menéndez Pelayo le dedicara en su implacable Historia de los heterodoxos españoles: «tan erudito como atrabiliario», con una estética «muy decadente, por no andar bien hermanados en su cabeza el buen gusto y la erudición inmensa» (1983: 283). Unas «páginas — según Pérez Vidal— dominadas por un tono de denuncia doctrinal e invectiva personal» (Gallardo, 1994: 16).

Como sostiene Bozal (1982 y 2004), nos encontrábamos ante un texto -y aquí radica parte de su carácter extraordinario- cuya construcción literaria se realiza bajo las coordenadas de la configuración grotesca moderna del mundo político y social, en un intenso diálogo ético y estético, por ejemplo, con los grabados y las Pinturas Negras de Francisco de Goya, como ya ha subrayado la crítica (Rodríguez Moñino, 1952; Glendining, 1982).

Una obra, por tanto, que debe considerarse como uno de los puntos de arranque de la modernidad peninsular, aunque parte de su andamiaje haya que situarlo en la mejor tradición española - algunas de sus fuentes son sus admirados Cervantes, Góngora o Quevedo-, en el fecundo itinerario de la parodia literaria, en la literatura de burlas y en determinados ámbitos clandestinos y heterodoxos del pensamiento español, donde destacan, entre otros, la estela de sermones jocosos o burlescos de finales del XVIII de fuerte carácter anticlerical (La Parra y Suárez, 1998). Una serie de textos con los que su autor se encontraba bastante familiarizado (Azáceta, 1962; Gallardo, 1968), y que junto a sus lecturas francesas (Pérez Vidal, 1996) servirán para construir una prosa original, donde se encontrarán importantes cambios respecto a esas tradiciones anteriores de camino también hacia la reconsideración del discurso satírico, tal y como quedará reformulado en la obra de autores como Mariano José de Larra (Bozal, 1982: 51-52), sin olvidar su esquiva trayectoria a través de los exilios liberales del 14 y del 23 (García Castañeda, 1982 y 1995) o los años del Trienio Liberal (Freire López, 1988a, 1988b).

En cualquier caso, con estas complementarias fuerzas entre lo tradicional y lo nuevo, y siempre en clave de parodia intertextual, el Diccionario de Gallardo inicia su «Introito» con «los duelos y quebrantos que la patria padece» (Gallardo, 1811: I). Un guiño cervantino que sintetiza muchas tradiciones literarias y que vislumbrará como pequeño adelanto una parte que, a modo de columna vertebral, guiará la construcción ética, estilística y literaria de esta significativa obra satírica de principios del XIX. 
En este mismo sentido, tampoco había que olvidar su admiración por la figura de Miguel de Cervantes (Álvarez Barrientos, 2007: 8), que le llevará a preparar durante los años de su exilio una edición anotada del Quijote y una frustrada Vida de Cervantes, que sin embargo nunca llegarían a publicarse. Lo mismo ocurriría con su edición de las Novelas ejemplares y La tía fingida, trabajos que, finalmente, se perderán en los aciagos sucesos del día de San Antonio de 1823 (Rodríguez Moñino, 1965). Dichos proyectos de Gallardo se verán reducidos al final a sus comentarios en El Criticón (1835) y a su participación en la polémica del falso Buscapié con Adolfo de Castro, años después.

Pero volviendo a los «duelos y quebrantos», nos encontrábamos ante una explícita referencia que, además de cuestiones de estilo literario — su «gusto verdaderamente cervántico» (Senabre, 1975)—, por otro lado, también hacía referencia a la falsa religiosidad ${ }^{2}$. Esto es, con los «ayunos y quebrantos» se podía «quebrantar» el precepto eclesiástico del ayuno y la abstinencia. El plato, por tanto, podía servir para que en su ofrecimiento se descubriera a judaizantes o falsos conversos. Una metáfora culinaria, pues, de fuertes implicaciones religiosas y de significativa importancia estilística e intencional en la obra gallardiana, como se verá más adelante.

\section{ANTICLERICALISMO Y OSTRACISMO: LA «CONJURA DEL SILENCIO»}

Todo ello venía a colación porque uno de los objetivos prioritarios del Diccionario crítico-burlesco no era sino desacreditar mediante el ridículo, la burla y la sátira a determinados sectores e instituciones eclesiásticas que o bien se habían posicionado contra el liberalismo de las Cortes de Cádiz, o bien entraban en fragante conflicto con dichos ideales - tal era el caso de la Inquisición, a la que le dedicará un extenso artículo-. Y para ello, nada mejor que aludir también a determinadas tradiciones anticlericales de fuerte arraigo, prácticamente desde la Edad Media (Caro Baroja, 1980: 13-53), y que en toda la primera mitad del XIX tendrán una singular incidencia en la cultura literaria española: Blanco-White, Juan Antonio Llorente, los hermanos Villanueva, Miñano, Clararrosa, Salvá, Eugenio de Ochoa, etc... (Molina Martínez, 1998: 50-163). Era ahí, en parte, donde tenían su justo signifi-

2 Francisco Rico en su edición del Quijote anota que «duelos y quebrantos eran un plato que no rompía la abstinencia de carne selecta que en el reino de Castilla se observaba los sábados, podría tratarse de huevos con tocino» (Cervantes, 1999: 36). 
cado y relevancia estos «duelos y quebrantos» vistos desde la óptica del autor de la Apología de los palos, que muy pronto se convierte en uno de los símbolos más visibles del anticlericalismo de principios de siglo.

En cualquier caso, para comprender el alcance ideológico y literario del Diccionario, además de las fuentes de los «ideólogos» franceses, cuyas lecturas se encuentran en la base del pensamiento gallardiano (Pérez Vidal, 1996: 1051), también hay que considerar los excepcionales contextos políticos e ideológicos donde se genera el texto (Gil Novales, 1994; Muñoz Sempere, 1999), en parte como producto de esas mismas coordenadas culturales, que, sin embargo, muy pronto desbordará para convertirse en uno de los textos satíricos más duros y combativos de la cultura político-literaria del primer tercio del XIX (Romero Ferrer, 2012b). Un complicado estatus que condenará a su autor al ostracismo más radical dentro de la crítica española hasta mediados del XX, cuando ya aparecen los documentados trabajos de Rodríguez Moñino (1952, 1955 y 1965), y la continuación de Pérez Vidal (1999) que recupera el texto del Diccionario en 1994, una obra que no se editaba desde 1848. Previamente, Sainz Rodríguez en 1921 le dedicará una extensa monografía, aunque repitiendo los tópicos y la perspectiva de Menéndez Pelayo. Por esta razón excluiría el Diccionario de la edición de sus Obras escogidas (Gallardo, 1928).

Nos encontrábamos, pues, ante una lectura que había relegado a Gallardo y su diccionario a los terrenos del descrédito literario, cuando no al olvido más injusto, participando así, consciente o no de ello, de los mismos problemas de dialéctica política, religiosa, social e ideológica a los que aludía muy descaradamente en su obra, y que permanecerán latentes en la cultura española hasta la Guerra Civil, como bien subrayaría Andrenio - De Gallardo a Unamuno - en 1926, y que continuarán durante los cuarenta años del franquismo. Las tempranas palabras de Cánovas del Castillo no dejaban duda al respecto: «España no recordará en los tiempos futuros que hubo en ella un escritor por nombre Gallardo» (1851: 186).

Para comprender esta especie de «conjura de silencio» (Fontana, 1979: 70; 1993: 4), entre otros factores, conviene no perder de vista cómo en este tránsito de la Ilustración al Romanticismo se desarrolla en la literatura española la línea estética de lo grotesco a partir de los protocolos de la sátira y los géneros jocosos (el cuento, la poesía y el sueño satírico, el chascarrillo, la fábula, etc...) que encontrarán, precisamente, en el crispado ambiente de la Guerra de la Independencia y las Cortes de Cádiz, un amplio campo de experimentación como arma de confrontación y réplica ideológica (Bozal, 2004). 
Unas coordenadas donde se inserta esta obra, en relación también con la compleja metamorfosis que sufre el mundo del escritor hacia el mundo público de la política, pues en la mayor parte de los casos «los literatos españoles se habían convertido... en políticos», como algunos años más tarde - 1834 - censurará Alcalá Galiano para referirse a la nueva República literaria (1969: 37; Álvarez Barrientos 2004: 11-24; Romero Ferrer, 2012a). El Diccionario de Gallardo era no solo el resultado de todo ello, sino además uno de sus ejemplos más extremos y conseguidos, tanto por sus contenidos ideológicos, como por la excepcionalidad de su lenguaje literario y la valentía de su autor que no se esconderá en el anonimato, como era frecuente en este tipo de prácticas literarias, para hacer públicas sus ideas y, muy especialmente, su censura moral e ideológica de la España de su tiempo.

\section{3. «CASTIGAT RIDENDO MORES»: LA MODERNIDAD DE LA SÁTIRA GROTESCA O LA IMPOSTURA DE GALLARDO}

Desde una perspectiva historiográfica, y de acuerdo con la formación ilustrada de Gallardo, conviene no perder de vista las transformaciones funcionales que desde la Ilustración se habían introducido en la sátira como género y forma literaria, ahora mucho más pragmática y ampliamente secularizada, pues:

No se trata ya de amonestar al que cae en el pecado sino de corregir al que se extravía de la razón. En consonancia con la nueva mentalidad que se impone en esta época, el discurso satírico sufre un proceso de secularización y se convierte en un "eficaz instrumento educacional, correctivo y curativo en pos del establecimiento de un nuevo orden de convivencia que se basa en la razón». La sátira se ocupa ahora de todos los ámbitos de la sociedad y, con una intencionalidad constructiva, trata de ser, de acuerdo con la ideología ilustrada, útil al bien común (Uzcanga Meinecke, 2001: 425).

Sin embargo, sobre esta base, Gallardo intensificará de manera bastante extrema el plano cómico de lo grotesco. Algo que se puede explicar desde la lograda síntesis que nos ofrece el extremeño entre esta nueva corriente satírica de origen volteriano y la presente en la literatura del Siglo de Oro, que bien conocía dada su condición de filólogo y erudito. Una situación que tampoco resultaba nada ajena al contexto de confrontación ideológica y política donde se inserta el Diccionario y el tono belicista de toda la literatura de la época. 
En cualquier caso, el uso de la sátira grotesca debía entenderse como una especie de censura moral a determinada realidad, para, en consecuencia con esa misma lectura, proponer otro modelo respecto a ese mismo ámbito satirizado. Se produce, por tanto, un enfrentamiento entre dos modelos, cuyo punto de inflexión, encuentro o desencuentro no es sino el texto literario, que a su vez puede moverse dentro de diversos registros técnicos, entre los que hay que subrayar, fundamentalmente, la caricatura y la parodia como procedimientos de copias cómicas. Unas imposturas que, sin embargo, debido al fuerte componente moral, adquieren la profundidad y categoría de lo grotesco, porque esas referencias deformadas o absurdas de la realidad aparecen retratadas como elementos esenciales de la misma condición y naturaleza humana y no tanto como meras desviaciones cómicas, que sólo operarían en el plano más superficial del discurso como reclamo de lectura.

Es aquí, por tanto, donde surge la diferencia básica respecto a la tradición satírica anterior, de la que el nuevo formato se nutre, pero desde un cambio de perspectiva moral e intelectual, pues la sátira moderna ahora incorporará la estética de lo grotesco desde la superioridad intelectual de la nueva mirada, como elemento de diferenciación respecto a sus raíces y modelos, aunque nunca sin perder de vista las nuevas funciones que había incorporado el discurso de la Ilustración referidas a su condición pragmática.

Veamos algún ejemplo de cómo Gallardo nos propone su visión grotesca de la realidad, en este caso para referirse a esos sectores de la Iglesia contrarios al liberalismo. Así los describe el autor:

Para aumentar la fuerza de esta - que digamos - iglesia militante, sus caudillos han levantado bandera, allegando a su facción, amén de la cleriguesca, sin excluir capigorrón ni clerizonte, a cuanta gente lega pueden enganchar: caballeros y villanos, hidalguetes de gotera, hombres de capa y espada, gente de gallarusa, y..., por fin, de toda broza. En esta behetría sacro-profana se distinguen por sus circunstancias ciertos señores mayores, muy viejos ya para aprender oficios nuevos, optimistas apasionados de otros tiempos, y tétricos pesimistas del presente orden de cosas, los cuales están empeñados en persuadirnos que la máquina de este mundo no podía andar mejor que andaba; y no es sino porque rodaba la bola en derecho de su dedo (Gallardo, 1811: V-VI). 
Efectivamente, en relación con todo este ámbito, la categoría, pues, de lo grotesco incorpora además el discurso amargo de la ironía, que la emparenta con el humor, pero desde un distanciamiento - como se puede observar en el texto anterior- que aleja las sensaciones del lector ante ambas perspectivas, pues mientras lo humorístico implica un sentimiento de satisfacción - la risa placentera, sin más-, lo irónico por el contrario es un concepto metafísico que, en contraste con el optimismo del primero, pretende crear una decepción por parte del lector (Roster, 1978). Provoca, en última instancia, una risa amarga. Una perspectiva que ya había quedado intuida en las tempranas palabras de Ramón de la Cruz, en 1769, cuando para referirse a su sainete el Manolo lo subtitula «tragedia para reír o sainete para llorar». Toda una declaración de intenciones de las nuevas posibilidades de la literatura humorística, que poco a poco irá transitando otros caminos que muy pronto la alejarán de la simple condición cómica, para afrontar ya en el XX la aventura del descubrimiento, entre otros procedimiento estéticos, por ejemplo, del esperpento, siempre de mayores implicaciones morales y mayor profundidad conceptual.

Pero volviendo al marco teórico de la ironía, la mirada irónica implicaría por tanto una fuerte ruptura y, en consecuencia, un alto grado de intertextualidad en el sistema literario que utiliza el autor. Algo que resulta de extrema importancia en su recepción, ya que el interlocutor debe conocer, o al menos intuir, el código que se utiliza para poder así descifrar y percibir la profundidad del mensaje. Por otro lado, a todo ello, desde un punto de vista estrictamente técnico, también ayudarán las interrelaciones que se establezcan entre el lenguaje irónico y los recursos propios de la parodia, pues toda ironía es una parodia implícita, aunque no siempre al revés, independientemente de que existe una ironía que se limita tan solo a señalar el escándalo y otra - que es la que interesa subrayar aquí- que colabora personalmente con dicho escándalo, de acuerdo también con una estructura lingüística que opera en diferentes niveles de interrelación no siempre recíproca.

Este tipo de construcciones literarias, de fuerte carácter crítico y contenido político, tiene una significativa relevancia en la España del primer tercio del XIX (Freire López, 1988), al amparo de la prensa y la publicística político-satírica, en especial durante los años de la Guerra de la Independencia, las Cortes de Cádiz y el Trienio Liberal. Una 
situación de la que Gallardo y su Diccionario deben considerarse su mejor ejemplo.

\section{EL DICCIONARIO COMO RESPUESTA Y RÉPLICA EN LA «GUERRA DE PLUMA»}

Gallardo escribe su Diccionario como réplica en tono de burlas a la publicación aparentemente anónima del Diccionario razonado ${ }^{3}$, una obra de fuerte carácter reaccionario del diputado Justo Pastor Pé$\mathrm{rez}^{4}$, que a su vez pretendía una parodia del modelo volteriano dentro de la línea ideológica de otro diccionario, el Diccionario antifilosófico, del abate Claudio Adriano Nonote, que se había publicado como refutación seria al Dictionnaire philosophique. Un texto no traducido al español por razones más que obvias, y que sin embargo en su momento sí fue objeto también del juego de las réplicas y contrarréplicas, muchas de ellas de tono jocoso (Quemada, 1967: 567-634). El Diccionario razonado, junto con el de Gallardo, inauguraba así para el XIX la tradición burlesca de los diccionarios, como respuestas y contrarrespuestas cómicas al furor lexicográfico de la Ilustración (Román, 2004), especialmente la Ilustración francesa (Álvarez de Miranda, 1984: 155).

En este sentido, el Diccionario crítico-burlesco resultaba un espléndido modelo de este interactivo sistema de comunicación literaria, pues en él se dan de manera muy excepcional la mayor parte de esas cualidades morales e intelectuales propias de la mirada grotesca que, arropadas bajo el humor destructivo del dardo envenenado de la palabra sobre la base de la ironía paródica, adquieren el valor y la autoridad del juez implacable en el que se convierte el autor, respecto a un mundo representado en la obra objeto de la burla. Un texto, este último, que hacía valer en plena contien-

3 De acuerdo con la documentación manejada debe de haber más ediciones del Razonado con otros suplementos y añadidos posteriores, a tenor de la nota que acompaña la segunda edición: «Advertencia sobre esta segunda edición: por haber salido un escritor intruso con un suplemento bien miserable al diccionario que debiera haber respetado, me he resuelto al fin a reimprimirle con el aumento de más de cincuenta voces o artículos». Por otro lado, Gallardo también se refiere en varios momentos a una continuación del Diccionario razonado (Rodríguez-Moñino, 1955: 90).

4 El Diccionario razonado ha sido atribuido a Justo Pasto Pérez por Ramírez Aledón (1996), aunque en el momento de su publicación las sospechas de su autoría, de las que se hizo eco Menéndez Pelayo, cayeron sobre el diputado absolutista gallego Manuel Freire Castrillón, y que es a quien alude Gallardo en algunos fragmentos de la obra. 
da ideológica en torno al nacimiento de la Nación moderna las armas y las formas del Antiguo Régimen, bajo la técnica de la parodia tradicional respecto a los referentes liberales. Una publicación -el Diccionario razonado-, por tanto, de fuerte carácter reaccionario que sintetizaba el pensamiento servil del momento y que tendría una cierta difusión en el Cádiz doceañista, con al menos dos ediciones en 1811, como síntesis de lo que podríamos denominar como «filosofía rancia». Esto es, el pensamiento reaccionario de autores como el beato Diego José de Cádiz - reeditado en esos años-, el capuchino fray Rafael de Vélez, autor del Preservativo contra la irreligión de 1812 y la Apología del altar y del trono de 1818, o el dominico fray Francisco Alvarado con sus famosas Cartas críticas del Filósofo Rancio - donde se emplearía a fondo contra Gallardo- , de profundo calado en la escasa cultura política española, incluso hasta bien entrado el XX (Novella Suárez, 2007), cuyo mito reaccionario se difundirá esencialmente en el Cádiz de las Cortes (Herrero, 1988: 259$341)^{5}$. El texto de Gallardo era una respuesta incisiva a todo ese mundo, dentro de un contexto más general que se llegaría a denominar en la época como la «guerra de pluma» (El Conciso, 16-I-1814: 2).

De una u otra manera, el autor utilizará los mecanismos y las técnicas cómicas de aquel, pero identificando dicho pensamiento con una realidad que formaría parte esencial de la condición humana del contrincante político. La agudeza lingüística, su profundo conocimiento del rival, su amplia cultura filológica y, muy especialmente, su carácter provocativo transformarán rápidamente el Diccionario crítico-burlesco en una obra de referencia de la época, con varias de ediciones - más de cinco- ${ }^{6}$, réplicas y contrarréplicas (Gallardo, 1812a, 1812b, Gil Novales 1994; González Troyano, 1985; Muñoz Sempere, 1999), y que por razones de oportunidad política esperaría unos meses después de su impresión en 1811 para distribuirse finalmente en abril de 1812 después de ser nombrado Gallardo Bibliotecario de las Cortes, creando así una mayor expectación editorial, máxime si tenemos en cuenta que algunas de sus contestaciones se publicaron incluso antes de que saliera a la luz pública el texto de Gallardo.

\footnotetext{
5 En concreto, el padre Alvarado dedicó dos cartas enteras a refutar el Diccionario críticoburlesco, y para referirse a Gallardo comenta que «también el demonio puede y suele tomar figura humana». También el padre Vélez, en su Preservativo contra la irreligión, se referirá a la obra como un claro ejemplo de «irreligión», para girar hacia posicionamientos mucho más duros en su Apología del altar y del trono.

6 La obra siguió editándose, a veces de manera apócrifa, hasta 1848. Pérez Vidal (1999: 34-36) relaciona hasta un total de quince ediciones entre 1812 y 1848.
} 


\section{LA COMUNICACIÓN LITERARIA DE GALLARDO: COPIA, PARODIA E INTERTEXTUALIDAD}

Sin embargo, eso era solo el pretexto, pues su mundo referencial traspasaba los límites de una obra concreta, para articular un completo, complejo y riguroso discurso moral que, valiéndose de un humor corrosivo, desentrañara la condición ridícula y absurda de determinados sectores de la sociedad española de aquellos perturbadores momentos políticos, enfrentados ahora a sí mismos gracias al muy molesto espejo literario que les proponía Gallardo en su provocativo y refractario Diccionario $^{7}$.

Un espejo cuya configuración quedaba bien sintetizada, precisamente, en esos «duelos y quebrantos que la patria padece». Referencia introductoria nada ocasional, con la que el autor no pretendía sino desde el primer momento jugar con sus diversas tradiciones textuales y sus respectivos significados, dentro a su vez de la burla mayor que implicaba la parodia respecto a los modelos del sermón como género literario religioso, que también se va a utilizar en los diferentes planos estructurales y discursivos del Diccionario. Su elocuencia gerundina, parte del lenguaje, así como el sistema argumentativo que Gallardo utiliza en el mismo «Introito» son una prueba de ello. Una perspectiva intertextual que otorga cierta unidad a la obra, tanto desde el punto de vista estilístico como intencional, cuando a lo largo de todo el texto se utilizan muchos de los protocolos discursivos y referencias lingüísticas o históricas que remiten, de manera inmediata, al mundo religioso, aunque - eso sí- siempre en clave cómica y satírica. Así, por ejemplo, para referirse a determinadas órdenes religiosas y al clero secular, lo hace en los siguientes términos:

Ahora bien, estos infelices, así como nosotros los desterrados hijos de Eva, todo lo han perdido en estas tristes circunstancias. Todo, menos el apetito de poseer ilimitada y omnímodamente. El comer no se escusa, y no tienen qué; el vestir ni más ni menos, y délo Dios. Por otra parte, los tiempos en que las avecitas del cielo bajaban a traer a los siervos del Señor la pitanza en el pico, ya volaron. Cuando una comunidad no tiene que llevar a la boca, las campanas no se tocan solas para despertar la caridad de las buenas almas, como antes diz que se tocaban en los conventos de los padres de Teati. Vense

7 La publicación del Diccionario provocará una durísima contraofensiva, como recogen los trabajos de Gil Novales (1994) y Muñoz Sempere (1999), en la que incluso se incitaría al pueblo «a una conmoción, celebrando devotamente... la acción de quitar[le] la vida... como la obra más meritoria ante los ojos de Dios» (Gallardo, 1812b: 97). 
los pobretes sin rentas, sin refectorios, sin amas que los popen, sin devotas que los mimen, que los amadriguen, que los regalen el bocadito, el bote de rapé, y sobre todo el rico chocolate macho aromático y potencioso (Gallardo, 1994: III-IV).

Como consecuencia de todo ello, Gallardo nos ofrecía una multiplicidad burlesca, pues, por un lado, se nos proponía una parodia simple respecto a la realidad parodiada y, de otro, una intensa parodia intertextual, que remitía a su vez a la tradición de dicha metáfora culinaria, también presente a lo largo de toda la obra, de acuerdo con la teoría del banquete y la carnavalización bajtiniana (Bajtín, 1990), en primer lugar, sin olvidar sus otros significados morales ya utilizados antes del Quijote, referidos a las «cuitas e infortunios». Gallardo emparentaba así ambas acepciones, además de las referencias religiosas, para crear un nuevo uso como resultado último de la mezcla de todo ese mundo referencial y su nueva reformulación ahora en clave de crítica grotesca, en clave moderna.

En efecto, los «duelos y quebrantos» ya aparecían en el refranero español — «Yantar aquí es un encanto, si tomas duelos y quebrantos»—, como en los Cancioneros dentro de las secciones de burlas, unos materiales literarios conocidos y utilizados por Gallardo. También inician el Quijote con evidentes connotaciones anticlericales para referirse a los cristianos nuevos (Cervantes, 1999, I: 36). Sin embargo, consciente de esa línea interpretativa, Gallardo también recuperará su antiguo y castizo sentido moral — «cuitas e infortunios»- ya contrastado en autores como López de Gomara, Diego de Mendoza, Luis Zapata o Francisco de Quevedo, entre otros (Rodríguez Marín, 1916), pero siempre jugando de manera simultánea con todas sus posibles ambivalencias, significados y ambigüedades.

Así, esos «duelos y quebrantos» de Gallardo no son sino su proyección grotesca de la realidad, a partir de unas retóricas y unas ideologías «rancias» que, más allá de los excesos satíricos de la contienda servil-liberal de principios del XIX, tenían que ver con una cualificación del mundo fundamentada en la aniquilación del adversario, lo que se expresa a través de una estética basada en la violencia verbal. Una situación que, en el caso de la publicística y literatura reaccionaria de la época, alcanza su mayor radicalidad cuando se alude a conceptos o transformaciones sociales o culturales claramente vinculadas a los logros de la Revolución Francesa, y cuyos resultados más perniciosos se concentran en torno a la figura y la imagen del filósofo y el periodista, esto es, el nuevo escritor, como portador de un mundo «monstruoso», «contra-natura», «enfermizo» y «pestilente», que hace 
dudar a autores como el reaccionario padre Alvarado, quienes cuestionaban incluso su «substancia humana», y cuya descalificación, en términos siempre de fuerte violencia lingüística y semántica, alcanzaba a todo el tejido y cuerpo social, institucional y cultural de su entorno: es decir, el ámbito liberal. Pues el escritor moderno, el hombre de letras, se presentaba ahora como el portador de ese nuevo orden conceptual de la sociedad y sus también nuevas relaciones con el poder político, lo que implica a su vez la destrucción de un pasado muy inmediato, que bajo ningún concepto se resistía a su desaparición.

La configuración satírica, pues, del escritor y su entorno que se ofrecía en el Diccionario razonado como discurso de ese pasado ya obsoleto - punto concreto de la respuesta de Gallardo, que recogía a su vez la trayectoria de la imagen cómica del escritor durante la centuria anterior (Álvarez Barrientos, 2006) - hacía extremar la caricatura hacia posicionamientos muy absurdos respecto a la concepción tradicional, con lo que la dialéctica de los contrarios se garantizaba, siempre a favor — claro está - del juicio tradicional y en detrimento del filósofo, que aparecía ahora retratado como una figura cómica, disparatada y desquiciada. El resultado final es una argumentación errónea que, como subraya Bozal, solo puede calificarse desde un punto de vista cómico como «patafísica» (2004: 135). Los escritores o filósofos resultaban así, en palabras del diccionarista, «aquellos hombres que nunca pudieron llegar a estudiar las facultades mayores» (Anónimo, 1811: 32) y «los más finos», aquellos «que hacen alarde de no reconocer ley alguna divina y procuran rasgar y aun destruir todas las leyes humanas» (33). Para el anónimo autor, en definitiva, los escritores liberales eran, pues:

unos monstruos inmundos semejantes a las mujeres prostitutas de profesión, que por no querer aplicarse al trabajo, ganan el sustento con su cuerpo viviendo de su infamia, cuya semejanza está en que adonde quiera que van llevan las herramientas de su oficio (28).

En consecuencia, como si de una infección o epidemia se tratara, debían ser aniquilados, con el objeto de erradicar cualquier posibilidad de anarquía o caos, además de evitar también el «error moral».

Desde esta perspectiva tradicionalista, se conseguía con ello ofrecer una imagen del mundo como algo cerrado, jerarquizado de acuerdo con un orden establecido que podía verse en peligro por la acción del temido «filósofo», quien había osado cuestionar y desafiar la tradición, la monarquía y la religión, induciendo consecuentemente al error moral. Era, en 
definitiva, un claro posicionamiento enfrentado a la modernidad, del que el Diccionario razonado, al igual que otra mucha literatura de la época (Herrero, 1988: 259-341), era una intensa muestra de una lucha sin cuartel contra el enemigo, sobre el que se pretende construir una violenta imagen cómica, pues su objetivo último no es sino su aniquilación moral e intelectual, como unos años más tarde también ocurrirá en el terreno físico con la fuerte represión fernandina, especialmente durante la Década Ominosa.

Ahora bien, esta visión del mundo, según la mirada reaccionaria, al crear una imagen del adversario tan desquiciada, y encontrarnos simultáneamente con el «contrafactum» humorístico que supone el Diccionario crítico-burlesco, consigue el propósito contrario al que se persigue, pues el efecto del espejo literario de Gallardo lo que conlleva precisamente es crear una imagen refractaria de aquel. El resultado es que el adversario cae en su propia trampa grotesca, ante lo estrambótico de su propia argumentación, un discurso cerrado y de reacción negativa ante una realidad cambiante como eran las transformaciones políticas, sociales, culturales e ideológicas que había traído consigo el proceso revolucionario francés.

De una u otra manera, el caso es que la obra de Gallardo centra su atención en desarmar al autor del Diccionario razonado en su mismo terreno, mediante el uso de la ironía con la ratificación exagerada de sus argumentaciones, destapando así dicho discurso y su ámbito de pensamiento, en tanto en cuanto aparecen como realidades disparatadas en sí mismas, sin necesidad alguna de añadir o quitar nada, solo llevando a sus últimas consecuencias dichas líneas argumentativas mediante la perspectiva de la parodia lexicográfica. Un procedimiento que consigue del Diccionario críticoburlesco transformarse en una sátira muy radical, gracias a su carácter interactivo con el lector y con los responsables «anónimos» del Razonado, que inconscientemente actúan como autores mismos de sus propias caricaturas. Las respuestas, pues, del autor de la Apología de los palos a cada uno de los artículos y consideraciones del Diccionario razonado descubrían como grotescas cada una de las afirmaciones de aquel, mediante el efecto cómico de la parodia intertextual presente en el espejo refractario que supone la obra del extremeño. Así, por ejemplo, la voz «fanatismo», para el diccionarista:

es un duende que nadie da con él por más diligencias que se hacen para ello, y solo los filósofos lo conocen (31). 
A lo que añade Gallardo:

En primer lugar, el fanatismo no es un duende, sino una enfermedad físicomoral. Una enfermedad cruel y casi desesperada, porque los que la padecen aborrecen más la medicina que la enfermedad. Es una como rabia canina que abrasa las entrañas, especialmente a los que arrastran hopalandas. Sus síntomas son bascas, convulsión, delirio, frenesí. En su último período degenera en licantropía y misantropía, en cuyo estado, verdaderamente lastimoso, el enfermo se siente con arranques de degollar a todos los que no sienten o piensan como él, aunque sean de su misma sangre, máxime si chocan con sus intereses y apetitos, y aun quisiera hacer una hoguera y quemar a medio linaje humano (40-41).

Sin embargo, esta perspectiva cómica solo es posible desde el convencimiento pleno de la realidad parodiada y desde la evidencia de que el mundo que ataca el Diccionario razonado es también un mundo real, pero desprovisto de esa visión ridícula que se proyecta de él. Un enfoque que vuelve sobre sí mismo para transformarse en una imagen deforme del mundo que se pretende defender, como si de la mirada de un loco se tratara, de manera muy similar a la desquiciada visión cervantina de don Quijote ante unos simples molinos de viento, que aparecían en su imaginación como unos gigantes monstruosos. Se establecían así unas coordenadas que para el lector resultaban a todas luces ridículas, y que delataban como loco al propio don Quijote, como ahora también resultaba deforme, entre otros aspectos, por su exageración, oscuridad y barroquismo, el mundo moral propuesto desde del ferviente frente servil en la prosa burlesca de Pastor Pérez, el «anónimo» diccionarista.

\section{LA DIALÉCTICA DEL DICCIONARIO: VERDADERO O FALSO}

Estas son las líneas principales en las que se va a mover Gallardo, quien desde el principio establece, de acuerdo con su deconstrucción de la realidad, dos planos claramente diferenciados ya en el propio «Introito» de su Diccionario. De un lado, el mundo de las «tinieblas», como trasunto literario del objeto de su parodia respecto a los sectores serviles y clericales, y, de otro, el ilustrado mundo de la «luz», desde el que se propone la mirada irónica en relación con el primero: «Pero ¿qué nubarrón de polvo y humo se levanta hacia la Selva negra, que nos roba la luz del día?» (V), afirma Gallardo. 
Una oposición de contrarios que trasciende lo meramente retórico, incluso la referencialidad histórica de la contienda servil-liberal que, no obstante, también importa pues constituye el primer contexto básico de la obra, para mostrarse como un auténtico discurso de lo grotesco, mediante la utilización del contraste cómico y el lenguaje de la sátira. Una dialéctica entre verdadero y falso, dentro de una guerra de ideas sobre la base de un anticlericalismo que sirve como eje conductor de todo el Diccionario, y que se expresa de acuerdo con un fuerte lenguaje literario lleno de animalizaciones, exageraciones y deconstrucciones caricaturescas, recursos que no hacían sino retratar la identidad moralamoral más profunda del adversario. Animalizaciones como «cuervos» (I) o «morder y ladrar» (IV), para referirse a determinados sectores de la Iglesia, o expresiones como «vuestra religión es vuestro vientre» (VII), desposeían de toda humanidad al objeto del sarcasmo, que de este modo quedaba reducido a la caricatura o el garabato, según los casos, cuando no, para la degradación moral incluso se recurría al uso de la escatología como arma de destrucción, un procedimiento habitual en la estampa y la literatura satírica durante estos años de la Guerra de la Independencia (Reyero, 2009). Por ello, los frailes, para Gallardo:

Son animales inmundos que, no sé si por estar de ordinario encenagados en vicios, despiden de sí una hedentina o tufo que tiene un nombre particular, tomado de ellos mismos: llámase fraíluno. Sin embargo, este olor que tan inaguantable nos es a los hombres, diz que a las veces es muy apetecido del otro sexo, especialmente de las beatas, porque hace maravillas contra el mal de madre (50-51).

Gallardo se movía así en los terrenos de lo satírico mediante caracterizaciones y descripciones burlescas, especialmente las de carácter anticlerical, cuya tradición en la literatura española bien conocía debido a su afición a los textos antiguos (Gallardo, 1968). Así, por ejemplo, en el artículo «capilla» — «Pieza del hábito o vestuario de ordenanza que usan los religiosos de varias órdenes, llamada así porque sirve para cubrir la cabeza» (24) — alude a la obra del poeta sevillano Juan de Salinas y Castro, quien escribiría poemas burlescos, bastante agresivos, y epigramas y letrillas en tono hedonista, completamente alejados de la gravedad propia de su condición sacerdotal y reproduce una de sus composiciones burlescas:

Nuestros abuelos que - perdónenme sus mercedes - estaban llenos de abusiones, tenían un miedo cerval a las capillas, como puede verse por la adjunta composición que nos ha dejado escrita un eclesiástico de grande ingenio y virtud, que floreció a fines del siglo XVI (24-25). 
Sin embargo, estas caracterizaciones cómicas o satíricas aparecían ahora con una mayor profundidad moral:

La estampa de la que tiene cara de hereje se les ha puesto al ojo por la primera vez: el hambre les roe los intestinos. Concómelos la desesperación de no poder volver a las ollas de Egipto. Esto, claro está que no puede engendrar buen quilo. $Y$ así descomidos, trasijados y mohínos, aguzan el diente, y dan la tarascada mortal. Morder y ladrar, este es su ejercicio cotidiano. Pero no diré yo, como algunos naturalistas, que esto lo hacen porque son bichos dañinos. Hácenlo por estímulos de un natural instinto, para gastar la verdinegra bilis que les pudre los hígados: muerden en fin, porque tienen hambre (Gallardo, 1811: IV).

Una perspectiva que traía al presente muchos elementos de la iconografía de los caprichos goyescos, y que serían algo después la base de las famosas Pinturas negras y Disparates del pintor de Fuendetodos, un mundo estético y conceptual que se desarrolla bajo la atmósfera ética y moral del «sueño de la razón produce monstruos», pues como escribe el autor en su Diccionario:

el manto de la noche acaba de envolvernos en medrosas sombras. Los luminares del orbe parece que han extinguido todos su vivifica lumbre y-continúa la cita del Diccionario- en tanta lobreguez sólo se divisan de trecho en trecho fugitivos relámpagos, semejantes a los fuegos fatuos de las sepulturas (V).

Y es aquí donde encontramos, para referirse a ese mundo de la cultura, la religión y la sociedad española, una de las descripciones satíricas más explícitas y significativas, que se adelantaba a las estampas negras de Goya de algunos años más tarde:

Ya se dividen en pelotones, ya marchan en hileras. Que se acercan. ¿Raro uniforme es el que gastan! De encamisada van los unos; por fajas llevan otros, cual salteadores, ceñidos los rijosos lomos con sendos cordeles y sogas esparteñas: caperuzas y moriscos birretes se calan aquéllos en lugar de gorras o morriones. A la fe que no se decir si esto es ejército, mojiganga o procesión de disciplinantes $(\mathrm{VI})$.

En efecto, el objetivo de esta turba no es otro que «una continua invectiva contra la filosofía y la razón humana» (IX). Una idea central de toda la obra que articula el carácter en apariencia disperso de todos los breves artículos 
del Diccionario, que mantienen una especie de simetría circular respecto al «Introito», donde quedan expuestas y bien argumentas las ideas de Gallardo, que no son otras que los juicios derivados de su formación ilustrada y su interés por la filosofía, Diderot, d'Alembert, Condillac y especialmente los «ideólogos» Cabanis y Destutt (Gallardo, 1994: 18-20). Un discurso que partía de la base antropológica de un materialismo no mecanicista, la primacía de la razón, la búsqueda de la felicidad pública, la instrucción y el progreso y, como consecuencia de todo ello, la lucha contra la ignorancia, el fanatismo y la oscuridad, y la entronización del simbólico sol constitucional, de manera muy similar a como había ocurrido con los revolucionarios franceses en 1789, quienes habían depositado en las nuevas diosas de la Razón y la Libertad la potente antorcha que con su luz servía para iluminar el horizonte de «la verdad, la ciencia y la Revolución» (Reyero, 2010: 73-74), frente a un camino plagado de «tinieblas». En este sentido, no resultaba nada casual la identificación por parte de Gallardo de la Constitución de Cádiz con la «aurora de la felicidad», como también su propósito era su precisa defensa frente al ataque de los sectores reaccionarios, pues «no es otro el fin de la presente guerra, ni aspiran a menos para su completo triunfo, que abarrenar la CONSTITUCIÓN» (VIII).

Y la mejor defensa es un ataque. Un ataque que utiliza como arma el elemento transgresor de la sátira, para sacar a la luz las incongruencias, lo ridículo y lo grotesco de la realidad representada del enemigo, su mundo y sus ideas relativas al Antiguo Régimen y la construcción del mito reaccionario - fray Diego de Cádiz, Simón López, el padre Vélez, el Filósofo Rancio (Herrero, 1988: 151-256)—. Y para ello va a utilizar la deformación burlesca y la ironía moral en todos los niveles posibles, convirtiéndose en un auténtico maestro del escándalo mediante la palabra escrita, en un provocador firme del adversario que, gracias a este espejo moral que supone el Diccionario, se verá reducido a la categoría de lo más ínfimo, mediante la deformación, animalización, muñequización o cosificación de la condición humana, como puede verse en el siguiente texto, en este caso para referirse a esos «filósofos rancios»:

Ladrando así de hambre y rabia, hincan el diente canino aun a los de su mismo pelo; pintiparados en esto a los perros de Zurita, los cuales dice el común proverbio que cuando no tenían a quien morder, se mordían unos a otros (IV-V). 
Nos encontrábamos, pues, ante una técnica fundamentada en la confrontación de contrarios, pero sobre la base de un moderno lenguaje visual, que ya se había utilizado en los Caprichos, y que en Gallardo servía para diseccionar la realidad desde un doble plano moral que actúa, simultáneamente, como negativo y positivo de una misma fotografía: el plano moral positivo desde el que se posiciona el autor, que sería el mundo de la luz ilustrada de corte revolucionario y filosófico, y, de otro, el plano técnico negativo, que es el reflejo de esa misma luz sobre una realidad moral y físicamente deforme y, por tanto, ridícula o monstruosa. Un paralelismo técnico, temático e intencional que se puede rastrear en bastantes fragmentos del Diccionario. Así, por ejemplo, en la entrada de «público» se puede encontrar, por un lado, la visión del diccionarista, sobre la que se proyecta la mirada incisiva del extremeño que logra transformar «burlaburlando» dicha percepción, ahora ridiculizada mediante la comparación del mundo eclesiástico con el de los cómicos:

No me parece que ha sido muy feliz nuestro vocabulista manual en definir al público en estos términos: "el concurso de oficinistas, periodistas, e inquilinos de los cafés y más desocupados que asisten al teatro, a los cuales llaman los cómicos respetable público». Esta definición por de contado no es del día [...]

Sin que sea visto que yo quiera echarla de más primoroso, voy a probar si doy una idea más cabal del público, así burlaburlando según el estilo de mi señor el diccionarista.

Entrando en alguna iglesia ¿no ha reparado el curioso lector, en algunos instantes que haya tenido el espíritu desocupado esperando a que salga misa, algún retablo de Ánimas donde en confuso zurriburri está revuelto el rey con el carbonero, la monja con la ramera, el papa con el ladrón, el soldado con el fraile, la emperatriz con la verdulera; y en fin mezcladas y confusas gentes de todas categorías, sexo, edad, estado, nación, y lengua? Pues de tantas y tan varias gentes se compone el Público, señor de toda mi veneración. Véase ahora con cuánta razón los cómicos que como acostumbrados a figurar hasta las gentes de corona y cetro, distinguen por lo regular un poquito más de colores que algunas gentes de hisopo y corona, con cuánta razón, digo, llaman a tal ayuntamiento de personas respetable público (121-122).

Como puede observarse, el resultado final de «público» no era sino una abigarrada imagen de la sociedad, que se veía sometida así al discurso bajtiniano del aparente desorden y la mezcla de lo alto y de lo bajo — «la monja 
con la ramera»-, una estampa de fuerte carácter entremesil, que desacreditaba la definición del anónimo diccionarista.

Las oposiciones plásticas y literarias entre ambos niveles de significación de la realidad van a operar en todo el texto, de acuerdo también con un tipo de discurso retórico que se efectúa siempre en clave de intertextualidad, pues a Gallardo le interesa especialmente dejar muy claros los contrastes entre las dos percepciones, la suya y la de su oponente. Una sucesión, pues, de imágenes que a modo de pequeñas estampas o caricaturas suponían una corrosiva galería de retratos morales de determinados sectores de la sociedad española, liderados muy significativamente desde los cuerpos eclesiásticos. Un aspecto este de significativa importancia en el pensamiento gallardiano, con el que además la obra tomaría el testigo de ciertas tradiciones anticlericales españolas (Caro Baroja, 1980: 13-53), para ofrecernos una formulación completamente nueva del problema que, partiendo de la sátira o la burla ante la conducta del mito reaccionario, ambicionaba una dura y profunda crítica de los sectores sociales que se posicionan frente a la modernización política e ideológica del país, una «administración anticuada, inoperante y caótica» (Molina Martínez, 1998: 24), representada por un absolutismo y un mundo clerical, aún de fuerte presencia durante el primer tercio del XIX.

Gallardo recurre a los cervantinos «duelos y quebrantos» para certificar la autenticidad de su implacable mirada sobre la realidad y la vertiginosa estampa grotesca que nos ofrecía de la misma. Conocedor de la tradición satírica española, se sitúa bajo el paraguas de la carnavalesca metáfora del banquete, presente a lo largo de todo el Diccionario, para desde ese posicionamiento técnico «del mundo al revés», situarse también en un plano de superioridad moral e intelectual, y ofrecernos, como consecuencia de ambas coordinadas y sobre la base de la Revolución Liberal más extrema, las evidencias de un mundo cuyos cimientos se encontraban en fase de descomposición.

Nos hallamos, pues, ante una hábil construcción en términos dialécticos que quedan bien expuestos de manera muy explícita en la presentación introductoria, y que constituye todo un decálogo intelectual y moral de extraordinaria convicción ilustrada —una Ilustración radical, eso sí-, pero que se muestra desde el punto de vista técnico e intencional $-\mathrm{y}$ he aquí el elemento excepcional y novedoso de Gallardo- a través del tono corrosivo de la burla grotesca y el escándalo, que lo apartan del concepto del justo medio, así como de la discrecionalidad ilustrada, desde una hábil síntesis, 
como ya se ha indicado, de dos importantes tradiciones satíricas: la volteriana y la presente en la literatura española del Siglo de Oro.

\section{A MODO DE CONCLUSIÓN: EL DICCIONARIO COMO «IMPÍO Y ATROCÍSIMO LIBELO»}

De todo lo expuesto debe deducirse que el Diccionario suponía una actitud de reto, que tanto gustaba al autor, pues entre otras muchas cosas también era una deliberada impostura cómica con un enérgico tono provocador y propagandístico: algo que le traería numerosos problemas, como lo fue la fuerte y esperada polémica que desataría (Gil Novales, 1994), así como el injusto descrédito de la crítica posterior, que, todo lo más, llegaría a considerar el Diccionario sólo como una obra humorística -Alcalá Galiano (1969: 57-59), por ejemplo—, y cuyo punto de inflexión marcará las palabras de don Marcelino Menéndez Pelayo cuando entre 1880 y 1882 en el vademécum de la anti-España, su Historia de los heterodoxos españoles, se refiere a él y a su Diccionario crítico-burlesco como elementos desestabilizadores de la tradición nacional. Gallardo como hereje de la tradición española, de cuyo Diccionario llegaría a escribir:

Mucho menos vale el Diccionario crítico-burlesco, librejo trabajosamente concebido, y cuyo laborioso parto dilatóse meses y meses, provocando general expectación, que en los mejores jueces y de más emunctae naris, vino a quedar del todo defraudada, siquiera el vulgacho liberal se fuera tras del nuevo engendro, embobado con sus groserías y trasnochadas simplezas. Cualquiera de los folletos de Gallardo vale más que este, pobre y menguado de doctrina, rastrero en la intención (284).

Las opiniones de Menéndez Pelayo, que sin embargo para otras facetas de Gallardo mantendrá unos juicios más favorables, dentro de su concepción sobre el siglo XVIII (Álvarez Barrientos, 2012, Iglesias, 2008) curiosamente, tenían que ver - y mucho- con las propias controversias sobre los orígenes mismos del Diccionario, una obra a la que desde el primer momento se le negaría todo mérito literario e intelectual (Pérez Vidal, 1999: 101-106), dentro de una fuerte campaña de desprestigio y difamación de su autor que a partir de ese momento se incorporaría, en el mejor de los casos, al canon de la heterodoxia española, cuando no al olvido, o quedaría simplemente recluido en su condición cómica y excéntrica como «el iracundo bibliopirata, villano de La Alberquilla», según acuñaría Adolfo de Castro en 1851 en sus Aventuras literarias del iracundo estremeño Don Bartolo Ga- 
llardete escritas por Don Antonio de Lupián Zapata (la horma de su zapato). Un testigo que parecía tomar el polígrafo santanderino con una contradictoria mirada que se debatía entre una cierta admiración filológica y el más severo de los rechazos ideológicos, por este «impío y atrocísimo libelo» (285). Sobre el Diccionario escribiría:

Ignaro el autor de toda ciencia seria, así teológica como filosófica, fue recogiendo trapos y desechos de ínfimo y callejero volterianismo, del Diccionario filosófico y otros libros análogos, salpimentándolos con razonable rociada de desvergüenzas y con tal cual agudeza o desenfado picaresco que atrapó en los antiguos cancioneros o en los libros de pasatiempo del siglo XVI (284).

Consciente o no ello, el autor de la Historia de los heterodoxos apuntaba, en parte, en la dirección correcta al subrayar, aunque para censurarlo, esos «trapos», «desechos» y «desvergüenzas», que a Gallardo sirven para proyectar su imagen moral de la sociedad española, sobre la base de unas líneas que, tal y como se apunta, conectaban técnicamente con la «agudeza» y el «desenfado picaresco» de nuestra mejor tradición literaria española. Los «duelos y quebrantos que la patria padece» eran una clara evidencia de todo ello.

\section{REFERENCIAS BIBLIOGRÁFICAS}

ALCALÁ GALIANO, A. (1969). Literatura española del siglo XIX: de Moratín a Rivas, ed. V. Llorens. Madrid: Alianza. Título original: «Literature of the Nineteenth Century: Spain». The Athenaeum (abril-junio, 1834).

ÁLVAREZ BARRIENTOS, J. (ed.) (2004). Se hicieron literatos para ser políticos. Cultura y política en la España de Carlos IV y Fernando VII. Madrid: Biblioteca Nueva.

- (2006). Los hombres de letras en la España del siglo XVIII. Apóstoles y arribistas. Madrid: Castalia.

- (2007). «Bartolomé José Gallardo (1776-1852) y Miguel de Cervantes». Ínsula 727-728, 8-9.

- (2012). «Matices del rechazo: el siglo XVIII en la Historia de los heterodoxos españoles». En Historia de los heterodoxos españoles. Estudios, R. Teja y S. Acerbi (eds.), 15-51. Santander: PubliCan-Ediciones de la Universidad de Cantabria/ Real Sociedad Menéndez Pelayo.

ÁLVAREZ DE MIRANDA, P. (1984). «Algunos diccionarios burlescos de la primera mitad del siglo XIX (1811-1855)». Romanticismo 2, 155-167. 
ANDRENIO (1926). De Gallardo a Unamuno. Madrid: Espasa-Calpe.

ANÓNIMO (1811). Diccionario razonado manual, para inteligencia de ciertos escritores que por equivocación han nacido en España. Aumentado con más de cincuenta voces, y una receta eficacísima para matar insectos filosóficos. Obra útil y necesaria en nuestros días. Cádiz: Imprenta de la Junta Superior.

AZÁCETA, J. M. (1962). El Cancionero de Gallardo. Edición crítica. Madrid: CSIC.

BAJTÍN, M. (1990). La cultura popular en la Edad Media y el Renacimiento. El contexto de François Rabelais. Madrid: Alianza Editorial.

BOZAL, V. (1982). «Gallardo, Miñano y Larra en el origen de la sátira crítico-burlesca». Cuadernos Hispanoamericanos 388, 51-61.

- (2004). «Bartolomé José Gallardo, la sátira grotesca». En La razón polémica. Estudios sobre Bartolomé José Gallardo, B. Sánchez Hita y D. Muñoz Sempere (eds.), 133-140. Cádiz: Biblioteca Cortes de Cádiz.

CÁNOVAS DEL CASTILLO, A. (1851). «Cuatro palabras sobre el folleto titulado Zapatazo a zapatilla escritas en defensa de un amigo ausente y en desagravio de las letras mientras llegan otras más autorizadas». La Ilustración 24, 185-186.

CARO BAROJA, J. (1980). Aproximación a la historia del anticlericalismo español. Madrid: Istmo.

CASTRO, A. (1851). Aventuras literarias del iracundo estremeño Don Bartolo Gallardete, escritas por el buen Don Antonio de Lupián Zapata (la horma de su zapato). Cádiz: Imprenta de D. Francisco Pantoja.

CERVANTES, M. de (1999). Don Quijote de la Mancha, F. Rico (ed.). Barcelona: Instituto Cervantes/Crítica.

CORTÉS, R. (1986). Teoría de la sátira. Cáceres: Universidad de Extremadura.

FONTANA, J. (1979). La crisis del Antiguo Régimen. 1808-1833. Barcelona: Crítica.

- (1993). «Prólogo». En Diccionario crítico-burlesco, 1-4. Barcelona: Alta Fulla.

FREIRE LÓPEZ, A. M. ${ }^{\text {a }}$ (1988a). «La fábula como forma de sátira política en la España de principios del siglo XIX». En De la Ilustración al Romanticismo. III Encuentro: Ideas y movimientos clandestinos, 303-315. Cádiz: Servicio de Publicaciones de la Universidad de Cádiz. 
FREIRE LÓPEZ, A. M. ${ }^{a}$ (1988b). «Fábulas políticas en 1822». En Varia bibliographica: homenaje a José Simón Díaz, 289-298. Kassel: Reichenberger.

GALLARDO, B. J. (1811). Diccionario crítico-burlesco del que se titula Diccionario razonado manual para inteligencia de ciertos escritores que por equivocación ha nacido en España; y pues sobran justísimas razones, palo habrá desde los pies hasta el cogote. Jorge Pitillas. Cádiz: Imprenta del Estado Mayor General.

- (1812a). Cartazo al Censor General por el autor del Diccionario crítico-burlesco, con motivo de la abortiza impugnación al Diccionario, anunciada por las esquinas en son de excomunión. Cádiz: Imprenta del Estado Mayor.

- (1812b). Contestación del autor del «Diccionario crítico-burlesco» a la primera calificación de esta obra expedida por la Junta censoria de la provincia marítima de Cádiz. Cádiz: Imprenta Tormentaria.

- (1835). La Tía fingida ¿es novela de Cervantes? El Criticón 1: papel volante de Literatura y Bellas Artes. Madrid: Imprenta de I. Sancha.

- (1928). Obras escogidas, P. Sáinz Rodríguez (ed.). Madrid: Compañía Ibero-Americana de Publicaciones.

- (1968). Ensayo de una Biblioteca Española de libros raros y curiosos. Madrid: Gredos. Facsímil de la edición de Madrid: Imprenta y Estereotipia de M. Rivadeneyra; 1863-66 (T.1 y 2); y Madrid: Imprenta y Fundición de Manuel Tello, 1888-89 (T.3 y 4).

- (1994). Diccionario crítico-burlesco del que se titula Diccionario razonado manual seguido del Diccionario razonado, A. Pérez Vidal (ed.). Madrid: Visor.

GARCÍA CASTAÑEDA, S. (1982), «Costumbristas españoles en Inglaterra: observaciones sobre la obra de Blanco White, Valentín de Llanos y Telesforo de Trueba y Cosío». En Actas del VII Congreso de la Asociación Internacional de Hispanistas, celebrado en Venecia del 25 al 30 de agosto de 1980, 501-509. Roma: Bulzoni.

- (1995). «José Joaquín de Mora y la sátira política en las Leyendas Españolas (1840)». En Romanticismo 5. Actas del V Congreso (Nápoles, 1993). La sonrisa romántica (sobre lo lúdico en el Romanticismo hispánico), 117-123. Roma: Bulzoni.

GIL NOVALES, A. (1994). «Las críticas al Diccionario crítico-burlesco en la prensa de la época». En Mélanges offerts à Albert Dérozier, 119-136. Paris: Las Belles Lettres. 
GLENDINNING, N. (1982). Goya y sus críticos. Madrid: Taurus.

HERRERO, J. (1988). Los orígenes del pensamiento reaccionario español. Madrid: Alianza.

IGLESIAS, C. (2008). «Menéndez Pelayo y el Siglo de las Luces». En No siempre lo peor es cierto. Estudios sobre Historia de España, 501-539. Madrid: Galaxia Gutenberg/ Círculos de Lectores.

LA PARRA LÓPEZ, E. y SUÁREZ CORTINA, M. (eds.) (1998). El anticlericalismo español contemporáneo. Madrid: Biblioteca Nueva.

MARTÍNEZ BAJO, J. (2007). «Sueños, diálogos y viajes imaginarios: literatura y política en el Diario Mercantil de Cádiz (1810-1814)». En La guerra de pluma. Estudios sobre la prensa de Cádiz en el tiempo de las Cortes (1810-1814). Tomo I: Imprentas, literatura y periodismo, M. Cantos Casenave, F. Durán López y A. Romero Ferrer (eds.), 169-389. Cádiz: Servicio de Publicaciones de la Universidad de Cádiz.

MENÉNEZ PELAYO, M. (1983). Historia de los heterodoxos españoles. México: Editorial Porrúa.

MOLINA MARTÍNEZ, J. L. (1998). Anticlericalismo y literatura en el siglo XIX. Murcia: Universidad.

MUÑOZ SEMPERE, D. (1999). «Bartolomé José Gallardo y el Diccionario crítico-burlesco en la prensa reaccionaria del Cádiz de las Cortes: El Procurador General de la Nación y el Rey». Cuadernos de Ilustración y Romanticismo 7, 101-117.

NOVELLA SUÁREZ, J. (2007). El pensamiento reaccionario español (1812-1975). Madrid: Biblioteca Nueva.

PÉREZ VIDAL, A. (1996). «La recepción del pensamiento de los 'ideólogos' en la España de Carlos IV: la obra juvenil de Bartolomé José Gallardo». En El mundo hispánico en el siglo de las luces, 1051-1064. Madrid: Editorial Complutense.

- (1999). Bartolomé J. Gallardo. Sátira, pensamiento y política. Mérida: Editora Regional de Extremadura.

QUEADA, B. (1967). Les dictionnaires du français moderne, 1539-1863. Étude sur leur histoire, leurs types et leurs méthodes. Paris: Didier.

RAMÍREZ ALEDÓN, G. (1996). «Sobre la autoría del Diccionario razonado (1811)». Trienio 27, 5-26.

REYERO, C. (2009). «El poder es una mierda, la mierda es un poder. El combate escatológico por la libertad». En 1808-1812: Los emblemas de la libertad, A. Ramos Santana y A. Romero Ferrer (eds.), 473-503. Cádiz: Servicio de Publicaciones de la Universidad de Cádiz. 
REYERO, C. (2010). Alegoría, nación y libertad. El Olimpo constitucional de 1812. Madrid: Siglo XXI.

RODRÍGUEZ MARÍN, F. (1916). El Yantar de Alonso Quijano el Bueno. Madrid: Tip. de la Revista de Arch., Bibl. y Museos.

RODRÍGUEZ MOÑINO, A. (1952). Francisco de Goya y Bartolomé José Gallardo (Notas sobre sus relaciones). Madrid: Academia de Bellas Artes de San Fernando.

- 1955). Don Bartolomé José Gallardo (1776-1852). Estudio bibliográfico. Madrid: Sancha.

- (1965). Historia de una infamia bibliográfica. La de San Antonio en 1823. Realidad y leyenda de lo sucedido con los libros y papeles de don Bartolomé José Gallardo. Estudio bibliográfico. Madrid: Castalia.

ROMÁN, I. (2004). «El espíritu ilustrado y la tradición de los diccionarios burlescos». En Aufklärung: Literatura y cultura del siglo XVIII en la Europa occidental y meridional. Aufklärung: Littérature et cultura du XVIII ${ }^{\text {me }}$ siècle en Europe occidentale et méridionale, J. Cañas Murillo/ S. Schmitz (eds.), 185-194. Frankfurt: Peter Lang.

ROMERO FERRER, A. (2012a). «'Los literatos españoles se habían convertido todos en políticos': las nuevas funciones públicas de la escritura (1811-1870)». Trienio. Ilustración y Liberalismo 60, 67-90.

- (2012b). «El Diccionario crítico-burlesco de Gallardo y la polémica de la ley de imprenta». En El nacimiento de la libertad de imprenta. Antecedentes, promulgación y consecuencias del Decreto de 10 de noviembre de 1810, E. Larriba y F. Durán López (eds.), 307-323. Madrid: Sílex.

ROSTER Jr., P. J. (1978). La ironía como método de análisis literario. Madrid: Gredos.

SÁINZ RODRÍGUEZ, P. (1921). Don Bartolomé José Gallardo y la crítica literaria de su tiempo. New York/Paris: Revue Hispanique, LI.

SENABRE, R. (1975). «Notas sobre el estilo de Bartolomé José Gallardo». Revista de Estudios Extremeños 31, 333-345.

UZCANGA MEINECKE, F. (2001). «Ideas de la sátira en el siglo XVIII: hacia una nueva función en el marco de la ideología ilustrada». Revista de Literatura 126, 425-459.

Recibido el 8 de abril de 2013.

Aceptado el 19 de septiembre de 2013. 